\title{
QUEEN'S
UNIVERSITY
BELFAST
}

\section{'Making it real': evaluating the impact of service user and carer involvement in social work education}

Tanner, D., Littlechild, R., Duffy, J., \& Hayes, D. (2017). 'Making it real': evaluating the impact of service user and carer involvement in social work education. British Journal of Social Work, 47(2), 467-486.

https://doi.org/10.1093/bjsw/bcv121

Published in:

British Journal of Social Work

Document Version:

Peer reviewed version

Queen's University Belfast - Research Portal:

Link to publication record in Queen's University Belfast Research Portal

Publisher rights

(C) The Author 2015. Published by Oxford University Press on behalf of The British Association of Social Workers. All rights reserved.

This is a pre-copyedited, author-produced PDF of an article accepted for publication in British Journal of Social Work following peer review. The version of record is available online at doi: $10.1093 / \mathrm{bjsw} / \mathrm{bcv} 121$.

\section{General rights}

Copyright for the publications made accessible via the Queen's University Belfast Research Portal is retained by the author(s) and / or other copyright owners and it is a condition of accessing these publications that users recognise and abide by the legal requirements associated with these rights.

Take down policy

The Research Portal is Queen's institutional repository that provides access to Queen's research output. Every effort has been made to ensure that content in the Research Portal does not infringe any person's rights, or applicable UK laws. If you discover content in the Research Portal that you believe breaches copyright or violates any law, please contact openaccess@qub.ac.uk. 
'Making it real': evaluating the impact of service user and carer involvement in social work education

\section{Corresponding author}

Dr Denise Tanner,

Department of Social Policy and Social Work, University of Birmingham,

Edgbaston,

Birmingham

B15 2TT

d.I.tanner@bham.ac.uk

$+44(0) 1214142941$

Rosemary Littlechild,

Department of Social Policy and Social Work, University of Birmingham,

Edgbaston,

Birmingham

B15 2TT

r.j.littlechild@bham.ac.uk

+44(0)1214145728

Dr Joe Duffy,

School of Sociology, Social Policy and Social Work,

6 College Park

Queen's University

Belfast

BT7 1LP

Northern Ireland

joe.duffy@qub.ac.uk

+44(0)2890975909

Dr David Hayes,

School of Sociology, Social Policy and Social Work,

Queen's University

Belfast

BT7 1LP

Northern Ireland

d.hayes@qub.ac.uk +44(0)2890975971 
Making it real': evaluating the impact of service user and carer involvement in social work education

Abstract: Service user and carer involvement (SUCl) in social work education in England is required by the profession's regulator, the Health and Care Professions Council. However, a recent study of $83 \mathrm{HEIs}$ in England reported that despite considerable progress in SUCl, there is no evidence that the learning derived from it is being transferred to social work practice. In this article we describe a study that examines the question: 'What impact does SUCI have on the skills, knowledge and values of student social workers at the point of qualification and beyond?' Students at universities in England and Northern Ireland completed online questionnaires and participated in focus groups, spanning a period immediately pre-qualification and between six to nine months post-qualification. From our findings, we identify four categories that influence the impact of service user involvement on students' learning: student factors; service user and carer factors; programme factors; and practice factors; each comprises of a number of sub-categories. We propose that the model developed can be used by social work educators, service user and carer contributors and practitioners to maximise the impact of $\mathrm{SUCl}$. We argue that our findings also have implications for employment-based learning routes and post-qualifying education.

\section{Key words:}

Evaluation; impact; service user and carer involvement; social work education. 


\section{Introduction}

Service user and carer involvement (SUCl) has been a requirement of social work qualifying programmes in the UK for over a decade (Department of Health, 2002). In order to be validated as providers of qualifying and post qualifying training, Higher Education Institutions (HEIs) must demonstrate that service users and carers are engaged in all aspects of their programmes and since September 2014, service user involvement has been a prerequisite for approval by the profession's regulator, the Health and Care Professions Council (nd).

However, a recent study of $83 \mathrm{HEls}$ in England reported that despite 'impressive' progress in SUCl in social work education and significant benefits for services users, carers and students, 'there is no evidence of this learning being transferred to practice' (Wallcraft et al., 2012, p.5). In this article we ask: 'What impact does SUCI have on the skills, knowledge and values of student social workers at the point of qualification and beyond?' We outline what is currently known and then describe a study conducted at the University of Birmingham and Queen's University, Belfast that examined students' perceptions of the impact that exposure to service user and carer perspectives and experiences on their programmes had on their knowledge, skills and values at the point of qualification, and then again six to nine months after qualifying. We conclude by identifying: the levels at which SUCl appears to have impact; the different types of factors affecting impact; and the challenges involved in undertaking such research. 


\section{Current knowledge about the impact of SUCI in social work education}

There is now a significant body of literature about SUCI in many aspects of students' learning in university including particular activities such as admissions (Matka et al., 2010); large and small group teaching (Duffy, 2012; Tew et al., 2012); assessment of students' readiness to practice (Duffy et al., 2013; Skilton, 2011) and, more unusually, involvement in academic assessment such as of group presentations or reflective writing (Shoura-Kirk et al. 2012). There are also accounts of SUCl in students' practice learning and assessment (Advocacy in Action, 2006; Stevens and Tanner, 2006; Duffy and Hayes, 2012) and exploration of models of SUCl in post-qualifying education (Webber and Robinson, 2011).

The benefits of SUCI in social work education have been well rehearsed (see for example, Advocacy in Action, 2006; Branfield, 2009; Skilton, 2011; Duffy, 2012 and Tew et al., 2012) and can be summarised as helping students to:

- Gain greater insight and awareness into the perspectives of people on the receiving end of services

- Challenge stereotypical views of service users and carers and recognise their strengths

- Develop greater empathy with service user and carers

- See people in the context of their families and environments, but as separate from their carers, and work better with them in partnership

- Develop better communication skills

- Make links between theoretical learning and practice. 
Student criticisms of SUCl are less well documented, but include lack of diversity of contributors, over-emphasis on negative experiences (Anghel and Ramon, 2009), concerns about service user distress (Duffy et al., 2013), reluctance to accept assessment by nonacademic staff (Advocacy in Action, 2006) and judgements that contributions are too 'professional' and/or too 'anecdotal' (Baldwin and Sadd, 2006).

Benefits identified by service users and carers themselves from being involved in social work training include:

- Gaining in confidence and self-esteem (Matka et al., 2010)

- Being valued as respected partners in the learning process (Matka et al., 2010)

- Satisfaction from improving the quality of future social workers (Branfield, 2009; Stevens and Tanner, 2006)

- Transcending the 'victim' role - captured by Sadd $(2011, p .8)$ as 'We are more than our story'

- Developing skills and abilities which may open up future work or other opportunities (Duffy, 2006).

For service user and carers, the challenges are both practical and philosophical in nature. Many studies have identified difficulties with payments, particularly for people eligible for benefits, poor access or transport, inadequate training and support and a lack of clarity around roles (see for example, Branfield, 2009). Other barriers include academic cultures not acknowledging the value of SUCI (Branfield, 2009; Fox, 2011) and downplaying the status of knowledge gained from experience (Glasby and Beresford, 2006; Beresford and 
Boxall, 2012). Thus it is argued that far from empowering service users and carers, involvement can lead to further inequality, oppression and exclusion (Cowden and Singh, 2007; Warren and Boxall, 2009).

So far the literature reviewed here focuses on the advantages and challenges of SUCI in social work education from the perspectives of students, academics and the service users and carers involved, rather than its impact in practice. However, increased scrutiny of social work as a profession has raised questions about the outcomes of social work education (Carpenter, 2011), including the impact of SUCl (Irvine et al., 2014). Robinson and Webber (2012) modified Kirkpatick's (1967, cited in Robinson and Webber, 2012, p5) framework for evaluating educational programmes, previously adapted by Carpenter (2005). Their modified framework, reproduced in Table 1, identifies different levels of impact, from evaluation of changes in students' perceptions of the learning experience (Level 1), to changes in their attitudes, knowledge and skills (Level 2), to changes in their practice or organisational changes (Level 3) and culminating in evidence of positive outcomes for service users and carers (Level 4).

\section{Table 1 Framework for evaluation of educational programmes}

Robinson and Webber (2012) reviewed literature which described and evaluated the effectiveness of $\mathrm{SUCl}$ in social work education and found that all 29 papers contained evidence that students valued SUCl. However, only three showed evidence of changes in students' attitudes, skills or knowledge, and none showed evidence of changes in their 
behaviour, organisational practice or benefits to service users and carers in practice.

Robinson and Webber (2012) acknowledge the methodological difficulties of evaluating the impact of $\mathrm{SUCl}$ on practice, including that of attributing changes in individual or organisational practice to one aspect of training. Perhaps partly because of these challenges, there are few studies which attempt to evaluate the impact of involvement in qualifying education once students have qualified and are in practice.

Our study addresses this gap, exploring the extent to which students retain the skills, knowledge and values acquired from their exposure to $\mathrm{SUCl}$ whilst completing their professional training programme once they move into employment.

\section{Our study}

Our research was undertaken in two UK Universities: the University of Birmingham in England and Queen's University in Belfast, Northern Ireland. Both Universities have a wellestablished history of SUCl. The study was designed jointly and the data from each site was shared and analysed collaboratively. In both sites, the research team comprised two academics, two service user and/or carer contributors and a former student. Each University obtained ethics approval via its own processes.

We followed a cohort of undergraduate social work students who were in their final year of study at both universities and captured their perceptions of SUCl in their training at the point of qualification and six to nine months later. 
Our objectives were to explore:

1. Students' perceptions of learning from SUCl in terms of knowledge, skills and values and how they had applied and developed this learning in practice placements.

2. To what extent, as newly qualified social workers, they had maintained and developed these knowledge, skills and values and put them into practice, six to nine months after qualification.

3. Any potential obstacles or enabling factors they had encountered in the implementation of knowledge, skills and values acquired from SUCl.

4. Any examples of good practice which they had initiated as a result of exposure to SUCl.

\section{Methodology}

The research design involved two phases. Phase 1 addressed research objective 1 and Phase 2 addressed objectives $2-4$.

\section{Phase 1 Pre-employment baseline (Q1)}

1. In consultation with the service user, carer and former student team in each site, we established a pre-qualification baseline questionnaire using Survey Monkey. This contained both rating scales and the opportunity for free text. We sent this to all final year students at the end of their programme, exploring their experiences of different types of $\mathrm{SUCl}$ and their impact, their experiences on placement and their aspirations for future engagement with service users and carers. The questionnaire was 
completed by 14 students from a cohort of 59 at Birmingham ( $24 \%$ response rate) and 21 students from a cohort of 79 at Queen's (26\% response rate).

2. Following this, we invited all final year undergraduate students to participate in focus group discussions. Four focus groups were held, three at Birmingham involving a total of 11 students and one at Queen's, with 7 students. In both sites, each group was facilitated by an academic researcher and a service user or carer. The focus group discussions were audio recorded and fully transcribed. The questionnaires and focus groups covered many of the same areas, but the focus groups allowed for more in-depth discussion of the issues as well as allowing an alternative, potentially more enjoyable, mode of response for those who had not completed the questionnaires. As the questionnaires were returned anonymously, it was not possible to determine how many students who completed questionnaires also participated in a focus group.

3. We sought consent from all students who completed the questionnaire to be contacted about their willingness to participate in a follow-up interview in 6-9 months so that we could explore the longer-term impact of SUCl on their practice. Those who consented provided their personal contact details.

\section{Phase 2: 6-9 Months into employment (Q2)}

A. All students who consented to be contacted in Phase 1 were sent an email inviting them to complete a second questionnaire (Q2). This asked questions about their current employment (if any), the impact that SUCl was having on their practice, any barriers and/or facilitators to them being able to apply this learning in practice and any examples of good practice of SUCl that they had initiated. The 18 Birmingham 
students and 16 Queen's students who had consented to be contacted again were sent the invitation. Four students at Birmingham and five students at Queen's completed the questionnaire. The response rate was therefore $22 \%$ and $31 \%$ respectively.

B. All students who completed the Q1 questionnaires and agreed to further contact were also sent an email inviting their involvement in a follow-up telephone interview to explore these areas in more detail. It proved more difficult than expected to contact students, with some email addresses and/or phone numbers not functioning. Some students also felt that they could not provide us with any useful information as they were not working in a social work post. Telephone interviews were carried out with 7 out of the 13 students who had originally agreed to a telephone interview at Birmingham (54\%) and 3 students at Queen's (30\%) out of a total of 10).

Table 2 shows summarises student participation in the different data collection methods and stages.

\section{Table 2 Summary of data collection}

The service users, carers and former students were involved in designing the questionnaires, co-facilitating the focus groups and analysing the data. 
In Phase 1, thematic analysis of the focus group transcripts and the open questions in the Q1 questionnaire was undertaken independently in the two sites. The analysis was then compared and revised, with some linked themes being amalgamated and new themes being added. This resulted in a final table of agreed key themes with illustrations drawn from both sites. The same process was used for the Q2 questionnaire and telephone interview data in Phase 2.

\section{Findings}

Whereas all of the students in the Queen's sample completing the Q1 questionnaire were white UK ethnic origin, $36 \%(5 / 14)$ of the Birmingham sample declared their ethnic origin as Asian, Black or Mixed Race. Across both sites, $86 \%$ (30/35) of students were of white UK ethnic origin. This increased to 89\% (8/9) for completion of the Q2 questionnaire. There were no significant differences between the two sites in terms of students' age or gender. Across both sites, 89\% (31/35) of the students who completed the Q1 questionnaire were female and $69 \%$ (24/35) were in the $20-29$ year age category. The gender balance remained the same for those completing the Q2 questionnaire; there were slightly older students completing this questionnaire compared with Q1, but 55\% (5/9) were still from the 20-29 age category.

All 9 students who completed the online questionnaires completed 6-9 months after qualifying felt that their perception and understanding of service users and carers had been moderately or significantly influenced by service user involvement on the programme. 
The themes and categories identified from thematic analysis are shown in Figure 1 . The themes were grouped under four headings, according to the type of factor affecting the impact of learning from service user and care involvement in the programme:

- Student factors

- Service user or carer factors

- Programme factors

- Practice factors

Table 3 gives a definition of the categories identified under each of the four themes. The next section discusses the themes and categories, illustrating them with reference to participant responses in the questionnaires and focus groups. To distinguish the source of response, B or Q denotes Birmingham or Queen's; F denotes Focus Group; Q denotes questionnaire; and T denotes telephone interview.

Figure 1 Themes and categories

Table 3 Definition of categories 


\section{$\underline{\text { Student factors }}$}

a. Emotional connection: Students felt that their interest in direct service user experiences increased their responsiveness and eagerness to learn:

... you feel more engaged in a session from having someone's experience inform what you are learning ... sort of first hand...you're going to listen more and take more in and care more about what is being said. (BF2)

Their openness to learning heightened the emotional impact of hearing about service user experiences and this continued to resonate long after the event:

... you were able to get a kind of real empathy ... it kind of gives you that greater sense of putting yourself in their shoes and how would you want to be treated. (QF1)

Exposure to experiential knowledge from service users was felt to be closely aligned to social justice and the need for social workers to adopt a more critical and questioning stance in their work:

Definitely on an emotional level it hit home for me maybe how naïve I was. It made me really think about the reality of people's situations, and definitely I have carried that with me. It's made me want to ask service users more questions; it's made me want to open up more things. (QF1) 
b. Practice relevance: The impact of $\mathrm{SUCl}$ was increased when students could relate the individual experiences and perspectives relayed by service users and carers to social work practice, identifying the implications for them as practitioners:

Not having a return phone call to them is a big thing in their life. It makes you realise when you go back into practice, although it is only a little job on my 'to do' list, it's an important job because it's a big part of their life. (BF3)

c. Resilience: Students felt that they needed to be resilient to absorb the impact of service user experiences and commit to 'fighting the corner' for service users and carers in practice. The emotional impact of hearing about difficult experiences was greatest early on in the programme, with some students, especially those with less experience, acknowledging that they found some sessions overwhelming. However, other students felt that these sessions were 'eye-opening', both about the nature of service user experiences and the potential of the social work role to make a difference. Some students came with their own experiences as service users, adding to the difficulty of disentangling the impact of SUCl in the education setting:

I think a lot of the influence on my practice was from my own experiences myself ... I couldn't say how directly their (service users') influence overrode my own experiences. (BF1)

d. Reflection and reflexivity: Students felt that the impact of service user involvement in teaching was strongly related to their ability to reflect on practice and to be reflexive 
about their own roles and identity. Some sessions led by service users were followed by reflective exercises and this was experienced as a helpful model for embedding learning.

\section{Service user and carer factors}

a. Sharing direct experience: service users' willingness to share their experiences in direct face-to-face contact with students was felt to have the greatest impact on learning:

When you actually have a carer or a service user in front of you telling you their stories, it just seems more real than anything else. (BF1)

'Making it real' was an oft-used phrase; access to the concrete experiences of services and carers brought a stark clarity to issues that could become clouded by academic theorising and professional jargon. The opportunity to interact with service users was seen as particularly valuable:

You're just able to ask questions and interact ... You're kind of getting a wee bit more around that person and it's not just them in that situation, you're getting them in the whole situation if you can interact with them a bit better. (QF1)

Another value of face-to-face interaction with service users was the opportunity it gave to see people beyond the 'service user' label: 
....Mental health is only one part of you...... it doesn't define you. He was a father, he was a husband, he was a worker, he was so much more. (QF1)

b. Reinforcing the basics: Students felt that their learning was increased when issues raised by service users connected with key messages from other parts of the programme:

I think some of the things that came up in the service user experiences I already knew but to have it reinforced by someone saying it from their own experience helped. (BF2)

Much of this concerned social work values, in particular, the importance of showing service users respect and gaining their trust:

What sticks out is ... the message about being on time, not cancelling things, the heightened power differential in the relationship. I now always am sensitive to communicate respect, may be quite simple but important. This will always stay with me. (QI 2)

c. Raw experience: Students referred to some service user and carer contributors as being 'professionalised':

Service users that we ... met with, I found all of the edges, the rough edges had been knocked off. They have become very professional service users ... sort of like a sanitised version of a service user. (BF2) 
On the other hand, students described 'raw' experiences as having greater impact as these evoked and harnessed their own emotional responses. It also gave them experience in how to respond appropriately to emotion:

... especially in first year whenever you're still so inexperienced and you haven't been out on placement, and having somebody live there who is showing all these emotions, it gives you an idea of how you react to them and the feelings that you have whenever people have these emotions. (QF1)

d. Relevant experience: Students emphasised the importance of service users and carers having experience relevant to the subject they were involved in delivering; otherwise, their contribution lacked credibility:

We were given a set scenario ... the service user who was working with us had a background of depression but it was dealing with a young person who was self-harming and he was finding it difficult to relate to how this person was feeling ... It was basically a case of 'Here's a sheet'; it wasn't designed to go with the service users. (BF3)

\section{Programme factors}

a. Recruitment: The ability of programmes to recruit service users from diverse backgrounds and with a range of experience was seen as increasing the impact of SUCI as it gave the service users and carers greater credibility: 
One thing that l've noticed is that there is very little diversity, certainly ethnic diversity within the service users that we've been working with ... because when I was out on placement I was in a very ethnically diverse community and yet their voice has been lost on this programme. (BF3)

Some students at Queen's felt that there was a predominance of involvement by adult service users, rather than children and parents, whilst some Birmingham students commented that there was plenty of involvement of young people who had been 'looked after', but not of other family members. On both programmes, students wanted greater representation of marginalised service user experiences, such as asylum seekers and refugees, older people with dementia, people with multiple disabilities and parents subject to child protection proceedings.

b. Integration: Students felt that careful planning and scheduling of $\mathrm{SUCl}$ in the programme could increase its impact; most thought that it should be integrated across the whole programme according to a coherent plan:

It all seemed very compartmentalised, for those few sessions where we met with service users ... It just seemed like 'All this week we will just go off and do this with service users for a while' and then we did that, forgot about it ... It would have helped to have been pulled back to... our assignments; tying it back to our placements that the service user is the end result. (BF2). 
c. Clear value and purpose: The impact of involvement was seen to be enhanced if its value and purpose was clearly articulated to students. The focus group discussions identified examples where students had not been clear about the reason for service users and carers being involved in specific teaching sessions or exercises and they then struggled to see its relevance.

d. Varied and interactive methods: Students felt that programmes needed to use a range of methods of SUCI to engage and retain their interest. Opportunities to meet with service users and carers outside of the University were seen as a good way of extending and intensifying learning. Queen's students went out in small groups to visit service users in their own community settings. This encouraged informal interaction between service users and students and gave more opportunities for students to ask questions and take control of their learning. At Birmingham, some students and service users went on an international trip together and this was seen as creating new opportunities to learn from each other.

\section{Practice factors}

a. Enabling work conditions: In the online questionnaire completed by students 6-9 months after qualifying, insufficient time and high workloads were identified as the biggest barriers, preventing students from implementing the 'best practice' requirements that had been identified by service users. Students also referred to 
specific aspects of current practice, driven by policy and managerial dictates, that they felt conflicted with applying their learning from service users:

You were constantly trying to justify why somebody should get a certain service ... You're supposed to be working on the recovery principle that this person has strengths and abilities and inherent good, their own strength. You have to sit and talk about the deficits so that they can get access to that service. Surely that puts them back rather than putting them forward? (Q F1)

b. Supportive culture: Conversely, the values and attitudes of colleagues and managers were rated by students as the factors that most enabled or supported them in being able to apply their learning from service users and carers. Students found it harder to retain and apply what they had learned from service users and carers if those around them were unsympathetic or antagonistic to these approaches:

If you have a good team or support system that does help. When you have a team that is very stressful or you have managers who perhaps don't understand or are less supportive then you can find that your own practice and things start to slip because you are trying to catch up or work to a model that is inherently different to your own. (BF2)

c. Opportunities to apply knowledge: The learning from service users and carers had greater impact if it was applied, consolidated and developed. However, this depended on opportunities within the practice setting to work in partnership with service users 
and carers over a period of time. One student, working on placement with children in care in a statutory setting, described how she had drawn on the learning gained on the programme:

Throughout our teaching we had different people who have been in care themselves come in and I remember one of them saying about how they valued how social workers were very open with them and explained the processes properly or explained their rights ... One of my cases, I sat and went through - even very simple information like how what he said would be stored and who it would be shared with...... once I explained how things would be done then he was a lot more willing to open up and engage and understand the processes and things. So it was very helpful taking their experiences and putting them into practice. (BF1)

However, in many of the organisations in which students were employed interactions with service users were confined to fleeting encounters, dominated by administrative demands.

d. Retaining values: Students felt that retaining their social work values over time was critical to them being able to apply their learning from service users. As mentioned, a supportive organisational culture played a key role in this. However, experience, familiarity, complacency and nonchalance were seen as threats awaiting them in practice:

I want people to be respected; people are demoralised, they are only a number, I am only a number...There are few people I work with who will advocate for anybody, absence of 
passion, feeling people don't give a damn...I wonder are social workers losing their values? People talk about patients like they're a piece of meat. Am I also going to be like that? Has the system made people disillusioned? (QI3).

\section{Discussion: What have we learned?}

When reviewing our findings in relation to Robinson and Webber's (2012) framework, presented earlier, there is overwhelming evidence that students value highly the opportunities encountered during their social work education to meet with and learn from service users and carers (Level 1). This supports other research that has explored student experiences, as summarised in the first part of this paper. In terms of changes in their attitudes, knowledge and skills (Level 2), again there is abundant evidence that students feel that SUCI has developed their social work values, enhanced their skills and given them new perspectives on individual situations and wider social issues.

Students in focus groups at the end of their programmes and when followed up subsequently in employment via online questionnaires and telephone interviews could all give concrete examples of how the contributions of service users and carers had directly impacted on their social work practice (Level 3). Whilst it was easier for students to identify aspects of their own practice that could be traced back to service user and carer input on the programmes, there were also examples of organisational change that they attributed to service user and carer influence. For example, one student said that she had taken issues 
raised by young people in a community meeting back to a staff meeting to explore how these could be addressed.

Although service users and carers were involved as co-researchers in the research processes, they were not involved as participants, so it is not possible to comment on their view of the achievement of positive outcomes for service users (Level 4).This was a smallscale study and it would have added considerably to the complexity, cost and ethical issues to seek the views of service users and carers with whom the students worked when in employment (though service users and carers do commonly contribute to the evaluation of students' practice when undertaking practice learning as part of qualifying and postqualifying programmes). However, as far as the students were concerned, their learning from service users and carers increased their sensitivity to the importance of issues such as punctuality, reliability, open and clear communication, and efforts to engage in partnership working. Their ability to feel empathy with service users was seen as helping them to respond with humanity, rather than officialdom.

Students felt that changes in practice and positive outcomes for service users were heavily influenced by organisational factors such as workloads, the time available to spend with service users and by the values and attitudes of colleagues and managers and the culture of the wider organisation. Thus, even though they might themselves have fully absorbed the learning from service users and carers, they acknowledged that this in itself was not sufficient for the learning to be applied and good practice sustained. This accords with what is already noted by Tew (2006) about the importance of supportive and participatory 
employment cultures in the advancement and promotion of emancipatory practice with service users. The challenges presented by managerialism and its associated regulated and proceduralised modes of practice are not to be underestimated (Trevithick, 2014).

Our framework of factors influencing the impact of SUCl (see Figure 1 and Table 2) highlights the complexity inherent in both evaluating and strengthening impact since the relevant components include factors pertaining to: individual students themselves; service user and carer contributors; programme/programme design and delivery; and the organisations in which students practise, both in placements and when qualified.

Some of these factors resonate with other research on service user involvement in social work education. For example, the importance of incorporating diverse service user experiences was highlighted by students evaluating the impact of service user involvement (Irvine et al., 2014). Some work has already been undertaken to identify absent voices and highlight issues to be addressed if more inclusive involvement is to be realised (see, for example, Whiteford (2011) in relation to people who are homeless). Ensuring the representation of diverse backgrounds and voices is not just about social inclusion, important though this is; it is also about: encouraging students to remain open to learning; 'keeping it fresh' in terms of the learning opportunities available; ensuring that they remain challenged and stimulated by the input; and continually engaging their emotional responses. 
A key theme in student reflections on the impact of SUCl was that it helped them to empathise and form emotional connections with service users. This, in turn, was seen as rooting their practice in humanity. However, this needed to take account of the individual student factors, such as their previous experience and emotional resilience if they were not to become overwhelmed by the experiences they heard about. Grant (2014) stresses the importance of reflection alongside empathy, arguing that students need to be helped to develop their self-awareness and ability to manage their emotions. Without this, there is a danger that students can be distressed and develop defensive and unhelpful responses to service users' (and their own) emotions.

\section{Conclusion}

There are a number of challenges and limitations to this study. It had limited funding and was small-scale. The longitudinal element of following students up post-qualification and into employment proved problematic as students either did not respond to the invitation to complete a further questionnaire or telephone interview, could not be traced or felt that they had nothing new to say. There may be some positive bias in the findings in terms of those who had been more influenced by SUCI being more likely to agree to be involved in the research.

Small-scale research that attempts to evaluate impact inevitably faces the problem of attribution and this applied here. Even though students attributed their learning and changes in their practice to the involvement of service users and carers, how can we be 
certain that this was the main influence, rather than other factors? Some students acknowledged that their own experiences as service user or carers were significant in their learning while others talked about what they had learned from people they worked with as service users on placement. Disentangling the impact of these different learning mechanisms was not possible.

Including service user and carer contributors to the programme and former students as part of the research team helped to ensure that the research design and analysis reflected these perspectives. However, it is possible that service user or carer contributors facilitating the focus group interviews may have contributed to a positive bias, with students being keen to attest to their learning. Similarly, they may have wanted to please or impress the academic facilitators.

Ultimately this study only captures student views about the impact of service user involvement. More extensive research could include service user and carer, academic and employer perspectives. A larger-scale study, with independent researchers, could also use other methods, perhaps involving social media, to elicit responses from students once in employment. In these ways, future research might more readily capture the impact of service user involvement in education on social work practice.

Nevertheless, this study reinforces findings of other studies about the value that social work students place on their learning from service users and carers. Moreover, it takes this further in terms of providing some evidence that SUCI in social work education produces: 
changes in attitudes, knowledge and skills; prompts changes in students' own practice and, through this, some change in organisational practice; and leads to beneficial outcomes for service users.

Detailed analysis of the themes identified by students has enabled us to generate a framework of influences on the impact of SUCl, incorporating factors pertaining to: students; service users and carers; programmes; and practice. Table 2 that defines the categories may prove a useful tool for educators, service user and carer contributors and practice organisations seeking to develop and maximise the impact of $\mathrm{SUCl}$ in social work programmes. It highlights, in particular, the need for practice organisations to be sympathetic to the messages and lessons promulgated by service users and carers and supportive of these being carried forward in practice. While students can be instrumental in 'fighting the corner' for service users and carers in practice, ultimately organisational cultures and practices need to be receptive of and responsive to service user concerns if the potential impact of SUCI in social work education is to be realised. As Skilton (2011), drawing on work from Scheyett and Diehl (2004, cited in Skilton, 2011, p.309) suggests:

... the stresses and demands of practice may shift new social workers back to more traditional and stigmatising models of service delivery with empathy developed through exposure with service users during social work education quickly receding.

Whilst the attention of academic educators tends to centre on the 'input' of service users and carers to qualifying and post-qualifying social work education programmes, our findings 
suggest a need for greater attention to addressing the barriers and promoting the enabling factors presented in the workplace (see Table 2). This could include exploring schemes whereby service users and carers act as 'buddies' or mentors to newly qualified social workers, as well as ongoing collaborations with service users and carers in practice education and post-qualifying training initiatives. Research on ways of sustaining social work values 'against the odds' in practice is another contribution that could be made by the academy.

The significance of practice settings in supporting or undermining students/practitioners in their application of learning from service users and carers raises questions about the potential implications for employment-based learning routes to social work qualification. We also feel there is potential for post-qualifying social work programmes to re-connect newly qualified social workers with the value of service user knowledge. This would serve to refresh students to the key messages from this particular kind of knowledge alongside other knowledge elements involved in post qualifying training.

\section{Acknowledgements}

We would like to acknowledge the vital contribution of the service users, carers and students in Birmingham and Belfast who worked with us on carrying out this study. 


\section{References}

Advocacy in Action (2006) 'Making it our own ball game: Learning and assessment in social work education'. Social Work Education, 25(4), pp. 332-46.

Anghel, R. and Ramon, S. (2009) 'Service users and carers' involvement in social work education: Lessons from an English case study', European Journal of Social Work, 12(2), pp.185-99.

Baldwin, M. and Sadd, J. (2006) 'Allies with attitude! Service users, academics and social service agency staff learning how to share power in running social work education courses'. Social Work Education, 25(4), pp. 348-59.

Beresford, P. and Boxall, K. (2012) 'Service users, social work education and knowledge for social work practice', Social Work Education, 31(2), pp.155-67.

Branfield, F. (2009) Developing User Involvement in Social Work Education, Workforce Development Report 29, London, Social Care Institute for Excellence.

Carpenter, J. (2011) 'Evaluating social work education: A review of outcomes, measures, research designs and practicalities', Social Work Education, 30(2), pp. 122-40.

Cowden, S. and Singh, G. (2007) 'The 'User': Friend, foe or fetish? A critical exploration of user involvement in health and social care'. Critical Social Policy 27(1), pp.5-23.

Department of Health (2002) Requirements for Social Work Training, London, Department of Health.

Duffy, J (2006) Participating and Learning - Citizen Involvement in Social Work Education in a Northern Ireland Context, London, Social Care Institute for Excellence.

Duffy, J. (2012) Service user involvement in teaching about conflict -- an exploration of the issues. International Social Work, 55(5), pp. 720-39. 
Duffy, J., Das, C. and Davidson, G. (2013) 'Service user and carer involvement in role-plays to assess readiness for practice', Social Work Education 32(1), pp.39-54.

Duffy, J. and Hayes, D. (2012) 'Social work students learn about social work values from service users and carers', Ethics and Social Welfare. 6(4), pp. 368-86.

Fox, J. (2011) 'The view from inside': understanding service user involvement in health and social care education. Disability \& Society, 26 (2), pp.169-77.

Glasby, J. and Beresford, P. (2006) 'Who knows best? Evidence-based practice and the service user contribution'. Critical Social Policy, 26(1), pp.268-84.

Grant, L. (2014) ‘Hearts and minds: Aspects of empathy and wellbeing in social work students'. Social Work Education, 33, pp. 338-52.

Health and Care Professions Council (nd) Service user and carer involvement in education and training programmes, available online at $h t t p: / / w w w . h p c-$ uk.org/Assets/documents/10004167SUCstandardwebsiteinformation.pdf.

Irvine, J., Molyneux, J. and Gillman, M. (2014) “Providing a link with the real world': Learning from the student experience of service user and carer involvement in social work education', Social Work Education, Published online 23 September, 2014. doi: 10.1080/02615479.2014.957178.

Matka, E., River, D., Littlechild, R. and Powell, T. (2010) 'Involving service users and carers in admissions for courses in social work and clinical psychology : cross-disciplinary comparison of practices at the University of Birmingham'. British Journal of Social Work, 40(7), pp. 2137-54. 
Robinson, K. and Webber, M. (2013) 'Models and effectiveness of service user and carer involvement in social work education: A literature review' British Journal of Social Work, 43(5), pp. 925-44.

Sadd, J. (2011) 'We are more than our story': Service User and Carer Participation in Social Work Education, SCIE Report 42, London, Social Care Institute for Excellence.

Shoura-Kirk, E., Backhouse, B., Bennison, G., Cecil, B., Keeler, J. Talbot, D. and Watch, L. (2012) 'Mark my words! Service user and carer involvement in social work academic assessment', Social Work Education, doi: 10.1080/02615479.2012.690388.

Skilton, C.J. (2011) 'Involving experts by experience in assessing students' readiness to practise', Social Work Education, Social Work Education, 30(3), pp. 299-311.

Stevens, S. and Tanner, D. (2006) 'Involving service users in the teaching and learning of social work students: Reflections on experience', Social Work Education, 25(4), pp. $360-71$.

Stevensew, J. (2006) ‘Understanding power and powerlessness. Towards a framework for emancipatory practice in social work', Journal of Social Work, 6(1), pp. 33-51.

Tew, J., Holley, T. and Caplen, P. (2012) ‘Dialogue and challenge: Involving service users and carers in small group learning with social work and nursing students'. Social Work Education, 31 (3), pp.316-30.

Trevithick, P. (2014) 'Humanising managerialism: reclaiming emotional reasoning, intuition, the relationship, and knowledge and skills in social work', Journal of Social Work Practice, 28 (3), pp. 287-311. 
Wallcraft, J., Fleischmann, P. and Schofield, P. (2012). The involvement of service users and carers in social work education: A practice benchmarking study, Workforce Development Report 54, London, Social Care Institute for Excellence.

Warren, L. and Boxall, K. (2009) 'Service users in and out of the academy: Collusion in exclusion?' Social Work Education, 28 (3), pp. 281-97.

Webber, M . and Robinson, K. (2012) 'The meaningful involvement of service users and carers in advanced-level post-qualifying social work education: A qualitative study' British Journal of Social Work, 42(7), pp. 1256-74.

Whiteford, M. (2011) 'Square Pegs, Round Holes: Rough Sleeping and Service User Involvement?', Practice: Social Work in Action, 23(1), pp. 45-58, doi:

$10.1080 / 09503153.2010 .532547$ 
Table 1 Framework for evaluation of educational programmes

\begin{tabular}{|l|l|l|}
\hline Level 1a & Learner perceptions & $\begin{array}{l}\text { Students' views on their learning experience and } \\
\text { satisfaction with the training }\end{array}$ \\
\hline Level 1b & $\begin{array}{l}\text { Service user or carer } \\
\text { perceptions }\end{array}$ & $\begin{array}{l}\text { Service user or carer views on their involvement } \\
\text { experience }\end{array}$ \\
\hline Level 1c & Staff perceptions & Staff views on involving service users or carers \\
\hline Level 2a & Modification in attitudes & $\begin{array}{l}\text { A measured change in attitudes or perceptions } \\
\text { towards service users or carers, their problems, } \\
\text { needs, circumstances or care }\end{array}$ \\
\hline Level 2b & $\begin{array}{l}\text { Acquisition of } \\
\text { knowledge and skills }\end{array}$ & $\begin{array}{l}\text { A measured change in understanding the } \\
\text { concepts, procedures and principles of working } \\
\text { with service users or carers, and the acquisition } \\
\text { of thinking/problem solving, assessment and } \\
\text { intervention skills }\end{array}$ \\
\hline Level 3a & Changes in behaviour & $\begin{array}{l}\text { Observation of whether the newly acquired } \\
\text { knowledge, skills and attitudes are evident in the } \\
\text { practice of the social worker }\end{array}$ \\
\hline Level 3b & $\begin{array}{l}\text { Changes in } \\
\text { organisational practice }\end{array}$ & $\begin{array}{l}\text { Observation of wider changes in the } \\
\text { organisation/ delivery of care, attributable to } \\
\text { service user or carer involvement in an } \\
\text { educational programme }\end{array}$ \\
\hline Level 4 & $\begin{array}{l}\text { Benefits to users and } \\
\text { carers }\end{array}$ & $\begin{array}{l}\text { Assessment as to whether there is a tangible } \\
\text { difference to the well-being and quality-of-life of } \\
\text { service users or carers who receive social work } \\
\text { services }\end{array}$ \\
\hline
\end{tabular}

Robinson and Webber (2012, p.5) Adapted from Carpenter (2005) and Morgan and Jones (2009); original framework devised by Kirkpatrick (1967).

Table 2 Summary of data collection

\begin{tabular}{|l|c|c|c|}
\hline & Birmingham & Queen's & Total \\
\hline Questionnaires Q1 & 14 & 21 & 35 \\
\hline Focus group participants & 11 & 7 & 18 \\
\hline Questionnaires Q2 & 4 & 5 & 9 \\
\hline Telephone interviews & 7 & 3 & 10 \\
\hline Total & 36 & 36 & 72 \\
\hline
\end{tabular}


Table 3 Definition of categories

\begin{tabular}{|c|c|c|c|c|}
\hline \multicolumn{5}{|c|}{ THEMES } \\
\hline & STUDENT FACTORS & $\begin{array}{l}\text { SERVICE USER AND } \\
\text { CARER FACTORS }\end{array}$ & $\begin{array}{l}\text { PROGRAMME } \\
\text { FACTORS }\end{array}$ & PRACTICE FACTORS \\
\hline $\begin{array}{c}\mathrm{C} \\
\mathrm{A} \\
\mathrm{T} \\
\mathrm{E} \\
\mathrm{G} \\
\mathrm{O} \\
\mathrm{R}\end{array}$ & $\begin{array}{l}\text { a. Emotional } \\
\quad \text { connection: } \\
\text { Students are open to } \\
\text { learning from service } \\
\text { users and feel an } \\
\text { emotional connection } \\
\text { with the learning } \\
\text { event. } \\
\text { b. Practice } \\
\quad \text { relevance } \\
\text { Students are able to } \\
\text { see connections } \\
\text { between service user } \\
\text { experiences and their } \\
\text { own future practice as } \\
\text { social workers } \\
\text { c. Resilience } \\
\text { Students are able to } \\
\text { learn from the } \\
\text { challenging and } \\
\text { distressing experiences } \\
\text { of service users and } \\
\text { this motivates them to } \\
\text { 'fight the corner' for } \\
\text { service users in } \\
\text { practice. } \\
\text { d. Reflection and } \\
\quad \text { Reflexivity } \\
\text { Students are able to } \\
\text { reflect on their } \\
\text { learning from service } \\
\text { users. }\end{array}$ & $\begin{array}{l}\text { a. Sharing direct } \\
\quad \text { experiences } \\
\text { Service users have } \\
\text { face-to-face contact } \\
\text { with students } \\
\text { b. Reinforcing the } \\
\text { basics } \\
\text { Service users reinforce } \\
\text { key fundamental } \\
\text { messages. } \\
\text { c. Raw experience } \\
\text { Service users' } \\
\text { experiences are } \\
\text { presented as raw as } \\
\text { well as } \\
\text { 'professionalised'. } \\
\text { d. Relevant } \\
\text { experience } \\
\text { Service users have } \\
\text { experience of direct } \\
\text { relevant to the nature } \\
\text { of their input }\end{array}$ & $\begin{array}{l}\text { a. Recruitment } \\
\text { The service users } \\
\text { recruited represent } \\
\text { diverse backgrounds, } \\
\text { experiences and } \\
\text { identities } \\
\text { b. Integration } \\
\text { Service user } \\
\text { involvement is } \\
\text { integrated closely with } \\
\text { the rest of the } \\
\text { curriculum } \\
\text { c. Values and } \\
\text { purpose } \\
\text { The programme } \\
\text { communicates to } \\
\text { students a clear } \\
\text { purpose of } \\
\text { involvement activities } \\
\text { d. Varied and } \\
\text { interactive methods } \\
\text { The programme } \\
\text { adopts varied methods } \\
\text { of involvement. }\end{array}$ & $\begin{array}{l}\text { a. Enabling } \\
\text { conditions } \\
\text { The conditions of } \\
\text { practice enable the } \\
\text { application of learning } \\
\text { from service users } \\
\text { b. Supportive } \\
\text { culture } \\
\text { The values and } \\
\text { attitudes of other } \\
\text { practitioners/organisat } \\
\text { ions support the } \\
\text { application of learning } \\
\text { from service users } \\
\text { c. Opportunities to } \\
\text { apply learning } \\
\text { The practice setting } \\
\text { offers opportunities to } \\
\text { apply learning from } \\
\text { service users } \\
\text { d. Retaining values } \\
\text { The practice setting } \\
\text { upholds social work } \\
\text { values and supports } \\
\text { practitioners in } \\
\text { applying these values. }\end{array}$ \\
\hline
\end{tabular}


Figure 1 Themes and categories

Practice factors

- Enabling conditions

- Supportive culture

- Opportunities to apply learning

- Retaining values
Student factors

- Emotional connection

- Practice relevance

- Resilience

- Reflection and reflexivity

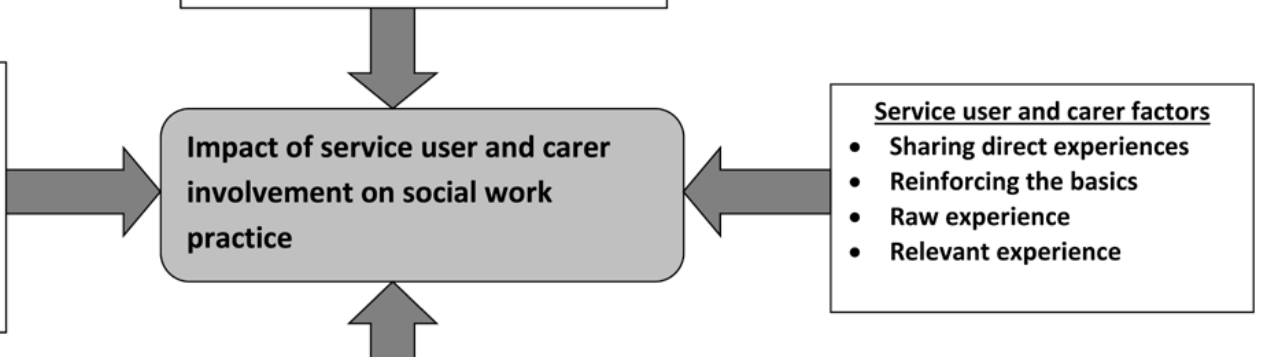

Programme factors

- Recruitment

- Integration

- Values and purpose

- Varied and interactive methods 